Richard O. Michaud

Acadian Asset Management

\title{
Investment Styles, Market Anomalies, and Global Stock Selection
}

The Research Foundation of

The Institute of Chartered Financial Analysts 


\section{Investment Styles, Market Anomalies, and Global Stock Selection}


(c) 1999 The Research Foundation of the Institute of Chartered Financial Analysts

All rights reserved. No part of this publication may be reproduced, stored in a retrieval system, or transmitted, in any form or by any means, electronic, mechanical, photocopying, recording, or otherwise, without the prior written permission of the copyright holder.

This publication is designed to provide accurate and authoritative information in regard to the subject matter covered. It is sold with the understanding that the publisher is not engaged in rendering legal, accounting, or other professional service. If legal advice or other expert assistance is required, the services of a competent professional should be sought.

The Institute of Chartered Financial Analysts is a subsidiary of the Association for Investment Management and Research.

ISBN 978-0-913205-91-5

Printed in the United States of America

January 1999

$\begin{array}{cc} & \text { Editorial Staff } \\ & \begin{array}{c}\text { Maryann Dupes } \\ \text { Editor }\end{array} \\ \text { Vivian Feggans } & \text { Jaynee M. Dudley } \\ \text { Assistant Editor } & \text { Production Manager } \\ \text { Cheryl L. Likness } & \text { Lois A. Carrier and Diane B. Hanshar } \\ \text { Production Coordinator } & \text { Composition }\end{array}$




\section{Mission}

The Research Foundation's mission is to identify, fund, and publish research that is relevant to the AIMR GlobalBody of Knowledge and useful for $A I M R$ member investment practitioners and investors. 


\section{Biogiraphy of the Author}

Richard O. Michaud is senior vice president and director of research at Acadian Asset Management. His research and consulting has focused on asset allocation, investment strategies, global investment management, optimization, stock valuation, portfolio analysis, and trading costs. Mr. Michaud has a Ph.D. in mathematics from Boston University and has taught investment management at Columbia University.

His prior positions include director of research and new product development at State Street Bank and Trust Company, head of equity analytics at Merrill Lynch, and director of quantitative investment services at Prudential Securities.

Mr. Michaud is a Graham and Dodd Scroll winner for his work on optimization, a director of the "Q" Group, and an Editorial Board member of the Financial Analysts Journal. He has recently completed the book Efficient Asset Management: A Practical Guide to Stock Portfolio Optimization and Asset Allocation, published by Harvard Business School Press (June 1998). 


\section{Contents}

Foreword $\ldots \ldots \ldots \ldots \ldots \ldots \ldots \ldots \ldots \ldots \ldots \ldots$, viii

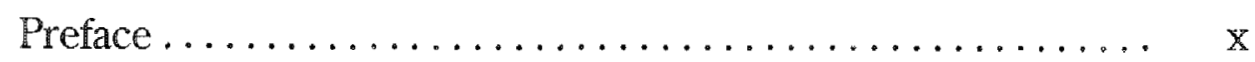

Chapter 1. Introduction...................... 1

Chapter 2. Investment Style Analysis ............... 3

Chapter 3. Market Anomalies in Global Equity Markets ... 5

Chapter 4. Institutional Style Factors $\ldots \ldots \ldots \ldots \ldots \ldots . \quad 9$

Chapter 5. Global Style Analysis ................ 17

Chapter 6. Market Efficiency and Factor Persistence...... 21

Chapter 7. Dynamic Factor Relationships............. 24

Chapter 8. Dynamic Factor Weighting ............. 28

Chapter 9. Defining Value and Growth Stocks......... 31

Chapter 10. Global Equity Style $\ldots \ldots \ldots \ldots \ldots \ldots \ldots . \quad 35$

Chapter 11. Summary and Conclusions ............. 37

Appendix A: Database Description ................. 39

Appendix B: Theil Factor Weight Estimation .......... 42

References............................... 43

Selected AIMR Publications .................... 47 


\section{Foreword}

For those of us who have made a career of studying stock returns, no paradigm has had a more pervasive impact on our thinking than the notion that capital markets are efficient. As someone with one foot in academia and the other in practice, I have long been struck by how opinions about market efficiency from both sides of the fence have evolved over the years. In more polemic times, academics were convinced by the weight of their self-generated evidence that it was impossible to "beat the market," particularly once active management fees were considered. Professional managers and analysts, perhaps feeling threatened by this assault on their livelihoods, were equally adamant that their services had value, citing as support numerous examples of colleagues whose performance records were too exceptional to have been driven by mere chance.

This deep schism in thinking typified the early years of the market efficiency debate. Indeed, finding someone who had or could be "converted" was rare. As one of my university colleagues noted, the discussion was as visceral and no less emotionally charged than an argument about which system of religious beliefs was the best. Although current opinions remain strongly held, recent years have nevertheless seen the verbiage moderate substantially for at least two reasons. First, money managers have found it increasingly difficult to outperform their unmanaged benchmarks (i.e., the buy-and-hold alternative espoused by efficient market purists). Second, academics have become increasingly suspicious of the sanctity of the case for market efficien$\mathrm{cy}$ in the face of a growing number of scientific studies documenting anomalous and contradictory behavior in stock return patterns associated with certain calendar events (e.g., weekends, January) or firm-specific characteristics (e.g., market capitalization, price-to-book ratio).

The root of the controversy is that establishing conclusively that markets are truly efficient is virtually impossible. That is, an analyst or investor cannot know for sure whether an observed stock price is too high or too low without having a theoretical model indicating what the "correct" price should be. This unfortunate situation leads to the so-called joint hypothesis problem, which, simply stated, means that any test of market efficiency is and must be a simultaneous test of the assumed valuation process. If stock return data disagree with our expectations, we are never really sure whether the security is actually mispriced or our mechanism for forming expectations is flawed. This distinction is hardly trivial, because mispriced securities can lead to profitable trading strategies and misspecified models can lead to financial ruin. It is not surprising then that practitioners and academics alike have begun to pay a great deal of attention to identifying the economic factors that drive stock re- 
turns and the factor models that summarize the return-generating process.

In this study, Richard Michaud provides the reader with a thorough analysis of the stock factor-stock return relationship and the role that these factors play in establishing anomalous market behavior. Importantly, he also extends this discussion to the definition of various popular investment styles-say, value versus growth-and considers these issues in the context of a global portfolio. He makes the point that it is possible to explain much of what is often attributed to anomalous factors (i.e., those that are significantly correlated with risk-adjusted stock returns) as being any of a variety of shortcomings in the researcher's empirical methodology. Notable examples of these afflictions include the inability to measure risk properly and the biases created by using a tainted data sample.

One of the most appealing features of this study is the presentation of a new global equity database specifically designed to overcome many of the empirical problems that have plagued past research in this area. Armed with this information, Michaud investigates return behavior in a handful of the world's major equity markets during the early years of this decade. Although the time frame he investigates is short and may not be representative of a more general period, the results he reports will comfort a lot of people while surprising many others. In particular, Michaud finds that there appear to be between two to four relevant factors but that the specific identity of these fac tors is highly dependent on the country in question. A practical implication of this finding is that value and growth stocks are quite likely to be defined differently throughout the world. Furthermore, two factors that are used frequently in style investing-firm size and price-to-book ratio-do not prove to be overly important. He concludes from this analysis that equity style investing does not yield a simple recipe that can be applied indiscriminately on a global basis.

I suspect that both academics and practitioners will find much to contemplate in this monograph. The story Michaud tells is one of caution but, ultimately, one that reaffirms the belief that financial market participants do not act in a wantonly irrational manner. Of course, the mere existence of any anomalous factors suggests that classical definitions of market efficiency may not be appropriate either. This is interesting and timely work that should provide a great deal of practical guidance to the current generation of money managers. The Research Foundation is pleased to bring it to your attention.

Keith C. Brown, CFA Research Director The Research Foundation of the Institute of Chartered Financial Analysts 


\section{Preface}

A stock factor, such as the earnings-to-price ratio, is said to be anomalous if it is statistically significantly related to ex post risk-adjusted return. A number of studies have documented the existence of anomalous stock factors in many global equity markets. Such factors may indicate the existence of market inefficiencies and profitable stock selection strategies. Practitioners often use these factors to select stocks and define investment style. Some recent studies have reported large risk-adjusted returns based on stock selection strategies that use anomalous factors.

The proper interpretation of many anomaly studies, however, remains controversial. A number of critiques indicate that the results may be explainable as mismeasured risk, econometric limitations, methodological errors, or data snooping. In addition, because many studies have not controlled for mandates of institutional asset management, the results may not have much practical investment value.

This monograph is devoted to understanding global factor-return relationships for institutional equity management and style analysis. A new global factor-return equity database has been designed to avoid a number of criticisms of market anomaly studies. In particular, the database was defined in December 1990 and allowed to evolve over time to limit the impact of data snooping.

Controlling for the many critiques of market anomaly studies in an institutionally relevant context significantly alters the perception of the economic significance of the anomalies in many equity markets. This new evidence is not consistent with two-factor style analysis, identical anomalous factors in global markets, the "irrational" behavioral hypothesis, or constant factorweight forecasting. The evidence is most consistent with market idiosyncratic inefficiencies and dynamic style factors. Notably, the perception that large active returns are available from constant factor weighting with little business or investment risk appears to be largely a hoax. A new "market culture" hypothesis is proposed and found to be useful for explaining a limited market inefficiency hypothesis in some global markets. The dynamic character of factor returns motivates development of an econometric procedure designed for implementing active factor tilts that may reduce forecast risk and increase stock selection reliability.

Conventional global equity style analysis is typically a generalization of U.S. style analysis. The results from analysis of global factor-return relationships raise important issues for the limitations of global style analysis. For ex- 
ample, global value style may be ambiguous, and strict adherence to a conventional value style for global equity portfolios may significantly limit investment performance. More generally, global style analyses may often be uninformative and misleading when characterizing the stock selection processes of many institutional equity managers.

This monograph reflects an ongoing effort to improve the technology of global stock selection and addresses practical issues in the management of global equity portfolios. The framework and data used to understand stock factors should lead to a better understanding of global equity investment issues. The analysis provides some useful information for all those involved in global asset management.

I particularly want to thank Richard Roll, Jay Shanken, Jonathan Berk, and Olivier Ledoit for very helpful suggestions and Paul Erlich for many valuable discussions and data analysis. I am very grateful to Mark Kritzman; Keith C. Brown, CFA; and James Scott for their encouragement and support. I gratefully acknowledge the assistance and support of my associates at Acadian Asset Management, particularly Gary Bergstrom, Raymond Mui, and Steve Silberberg, who were very helpful during various stages of this research. I am also grateful for the support of the Research Foundation of the Institute of Chartered Financial Analysts. I remain responsible for all errors.

I am happy to hear from readers. Please send comments, questions, and corrections to rmichaud@worldnet.att.net and visit my Web site at rmichaud.com for updates and errata.

Richard O. Michaud 



\section{Introduction}

The terms "value" and "growth" have a long history in equity management. They are widely used to describe investment managers and funds and to classify stocks. Traditionally, a value-stock manager focuses on finding undervalued stocks, in terms of a low stock price relative to firm fundamentals, such as earnings or book value. In contrast, a growth-stock manager focuses on finding stocks with high expected growth in earnings. A second dimension-size, or the market value of stocks in a fund-is also widely used to describe manager style and explain performance.

The goal of investment style analysis is to understand a manager's active return. The strong interest in investment style is part of a growing need by consultants and investors to better understand manager performance and specialization. The key to successful style analysis rests on whether a set of factors can be identified to reliably represent the active-return-generating process. Such a framework usually comes, at least in part, from market anomaly studies. A large body of academic and professional evidence demonstrates the existence of stock factors that are statistically significantly related to ex post return, after risk adjustment, in many equity markets and time periods. Such results appear to contradict the efficient market hypothesis and often form the basis of an active stock selection framework.

Active global stock selection poses many challenges to style analysis and equity management. The value of equities in various global markets may reflect wide variation in accounting standards, regulatory environments, political traditions, and characteristics of the economy and structure of financial markets. On the other hand, global stock selection represents the ultimate equity management frontier. The investment opportunities associated with reliable global stock selection can substantially enhance return per unit of risk relative to domestic equity investment (for a recent review, see Michaud et al. 1996).

A convenient framework for global equity management can be described as a three-or four-stage process: (1) stock valuation within each equity market, (2) equity market valuation within a global equity market index, and (3) scaling the two components of the forecast so that they are comparable. Active currency management may be considered a fourth stage of the process. The 
scope of this monograph is (cross-sectional) global stock selection within developed country equity markets. The goal is to present an institutionally relevant view of the active-return-generating process for global stock selection and style analysis. The discussion does not consider the issues of active country and currency selection (stages two through four), which are normally part of global equity management. Cross-sectional stock selection within a market can avoid consideration of the differences in accounting standards, regulations, and market structures among countries at the stock level. Also, stock selection procedures developed for the U.S. market can be applied, although basic assumptions of relatively reliable stock forecast data and of rational and relatively economically diversified markets must be satisfied.

This monograph reviews a spectrum of market anomaly studies, focusing on how they affect style analysis and global stock selection. It describes a new factor-return database developed for a number of global equity markets and designed to minimize the often-cited market anomaly criticisms for institutional stock selection. The data shed light on the active-return-generating process and on style analysis in five major equity markets. The results indicate that a small number of country-specific factors are significant in each market for the time period studied. The significant factors are not the same in all markets and, in most cases, not the components of traditional two-factor style analysis. In addition, the results are not consistent with the irrational behavioral hypothesis. However, a market "culture" hypothesis is helpful in rationalizing some patterns in factor-return relationships and may support an $e x$ ante (i.e., prior) assumption of market inefficiency in some cases. What forcefully emerges is the importance of addressing the idiosyncratic nature and dynamic character of markets for successful global equity management. To reduce forecast risk and enhance reliability and performance, a rigorous statistical estimation procedure is introduced that incorporates short-term exogenous information in active stock selection. The market- and time-period dependence of significant style factors raises important issues concerning the limitations of style analysis in global equity portfolios. 


\section{Investment Style Analysis}

When suitably defined, managers with similar investment styles are likely to perform more like each other than like the overall market or managers with different styles. Style analysis may be much more informative than peer-group analysis, which is commonly used by many performance analysis systems. In some cases, passive funds provide "style" returns, raising the issue of the role of style performance for active management. Proper style analysis leads to finding good managers within a given style and avoids having to fire a manager only because the manager's style is out of favor.

At least three different approaches to style analysis exist - consultant, academic, and practitioner.

Consultant style analysis focuses on a comprehensive description of a manager's investment process, including investment philosophy, portfolio characteristics, and subsequent returns (Christopherson and Williams 1995). Often when evaluating a manager, a consultant may view consistency of performance relative to investment philosophy as a major consideration in the decision-making process.

Academic style analysis, such as that found in Roll (1995), tends to equate style with market anomalies and focuses narrowly on the determinants of active stock returns. In an academic study of the functioning of capital markets, style factors may be important if they indicate informational inefficiencies and account for superior manager performance.

Practitioner style analysis is pragmatic and simply focused on forecasting return. Style factors may be useful in predicting active return over investment horizons of institutional interest, whether the factors are anomalous or ephemeral. Practitioners often make bets on episodic factors that may be related to active return over short- and medium-term time horizons. The factors in commercial risk models are often a convenient source of nonanomalous style factors used in forecasting return. ${ }^{1}$

The two popular analytical approaches for analyzing style are return-based and portfolio-based methods.

The return-based or "effective mix" procedure, which was popularized by

IOne representative case is Leinweber, Krider, and Swank (1995). 
Sharpe $(1988,1992)$, uses mean-variance optimization to attribute historical portfolio returns to various candidate indexes (for an example, see Hardy 1995). The advantage of this approach is simplicity and convenience. It does not require any more information than historical portfolio and index returns. Its limitations include the impact of noisy data on reliability and its likely inappropriateness for dynamic style managers. ${ }^{2}$

The portfolio-based method seeks to identify and attribute return to various factor "tilts" in the portfolio. ${ }^{3}$ The advantage of this approach is that it may be more reliable and useful for a wider array of managers, including dynamic style managers, than the return-based approach. Its limitations include the fact that period-by-period portiolio composition must be available for analysis.

An analytical equity style analysis requires a framework that identifies the essential components of active return. A style analysis framework often follows from the results of factor studies of cross-sectional market anomalies in global markets. Capaul, Rowley, and Sharpe (1993) proposed the use of twodimensional style analysis for global equity markets. This popular framework for equity style analysis uses the book-to-price ratio and market capitalization to define portfolio style. Exhibit 2.1 illustrates this procedure schematically. Based on this scheme, small-cap value managers invest in stocks with small market capitalizations and high book-to-price ratios. Style performance analysis compares their performance with that of other managers in the same category and not with the performance of managers in the remaining three categories. The following chapters review some of the results from identifying the significant components of return that are the basis of most style analysis frameworks.

\section{Exhibit 2.1. Traditional Style Analysis}

\begin{tabular}{lcc} 
& \multicolumn{2}{c}{ Book-to-Price Ratio } \\
\cline { 2 - 3 } Market Cap & High & Low \\
\hline Small & Small-cap value & Small-cap growth \\
Large & Large-cap value & Large-cap growth \\
\hline
\end{tabular}

${ }^{2}$ For an analysis of the statistical characteristics of the procedure, see Michaud 1998a, Chapters 6 and 7.

${ }^{3}$ Christopherson and Trittin (1995) provide a review of multivariate style analyses and a detailed description of an alternative based on portfolio characteristics. 


\section{Market Anomalies in Global Equity Markets}

A lot of evidence indicates that a number of stock factors are statistically significantly related to ex post cross-sectional returns for U.S. stocks, after risk adjustment, over reasonably long time horizons. The classical empirical studies include Basu (1977) on the earnings-to-price ratio, Litzenberger and Ramaswamy (1979) on dividend yield, Banz (1981) on firm capitalization, and Reinganum (1981) on a comparison of the earnings-to-price ratio with firm capitalization. These reports inspired a large number of "market anomaly" studies on such issues as seasonal factors (e.g., the January effect), firm fundamentals (e.g., book-to-price ratio), and price momentum. Notable empirical studies include Keim (1983) for turn of the year and firm market size; Rosenberg, Reid, and Lanstein (1985) for book-to-price ratio and specific return reversal; Fama and French (1992) for book-to-price ratio and market capitalization; and Lakonishok, Shleifer, and Vishny (1994) for two-factor models that include sales growth. Hawawini and Keim (1998) found similar factor-return relationships in many global markets.

As rationalized by Graham and Dodd (1962), investment professionals have used "value" factors, such as the earnings-to-price ratio, to select stocks for decades. Institutional investors have used various single-factor (Michaud and Davis 1982) and two-factor (Ambachtsheer and Farrell 1979) models for many years. Market anomaly studies provide a rationale for much of institutional active management practice. ${ }^{1}$

Although the existence of significant stock factor relationships with ex post risk-adjusted return is widely acknowledged, the interpretation of their economic significance is highly controversial. Important questions have been raised concerning the economic nature of the factor relationships. The critical issues for investment management include whether the factors are economically significant and persistent. The controversy also affects style analysis. If

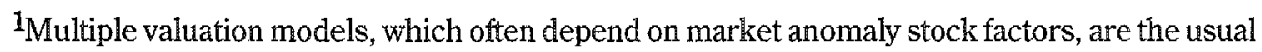
frameworks used by institutional active equity managers for forecasting return and active stock selection (Michaud 1990).
} 
the book-to-price ratio or capitalization has no economic significance in a given market, or if other factors are more significant, then traditional two-factor style analysis may have limited investment value.

The perception of economic significance and persistence of anomalous factor-return relationships depend on the underlying explanations for the relationships. At least nine rationales can be found for market anomalies-two that are consistent with market inefficiency and economic significance (ephemeral inefficiencies and irrational investor behavior) and seven that are not (misestimated risk, methodological errors, data snooping, misinterpretations of the size factor, attribute-sorted portfolio implications, econometric limitations, and magnified returns).

Ephemeral inefficiencies. Anomalous return factors in a market may simply indicate that capital markets are episodically informationally inefficient. This interpretation is the one favored by some early researchers and many investment practitioners. The absence of a fundamental rationale suggests that anomalies are unlikely to be reliably persistent over time. In addition, once a factor is identified as anomalous, its use may become widespread and its effectiveness is likely to diminish. Still, evidence shows that some market anomalous factors persist over relatively long periods (Reinganum 1981).

Irrational Belhavioral Hypothesis. An optimistic rationale for the economic significance of anomalous factors is the "behavioral hypothesis." In this view, market anomalies may represent consequences of "naive" or "irrational" investor behavior (for a recent discussion and references, see Lakonishok et al. 1994). Many market anomalies are classifiable as "value" or "contrarian" factors. Investors may be considered naive if they overreact to information and price changes, extrapolate past growth too far into the future, ride stock price trends without regard to firm fundamentals, or focus on firm attractiveness and fashionableness without considering price. Such investor behavior, if sufficiently widespread, may provide risk-adjusted profit opportunities for more rational, sophisticated investors with contrarian and disciplined strategies. Persistence may occur because many anomalies are inherently unfashionable and few investors are sufficiently "rational" to maintain a contrarian strategy against widespread market sentiment. Discussions of the rationality of investors often include references to psychological literature and experiments on decision-making errors. Currently, the behavioral explanation of market anomalies is itself fashionable, not incidentally because its message is often optimistic for value managers and because it provides a quasi-scientific veneer for many traditional explanations of persistent poor investment perfor- 
mance. At least seven alternative explanations, however, challenge the validity of the behavioral hypothesis.

Misestimated Risk. One rationale for the existence of market anomalies is that they reflect misestimated or omitted systematic risk (Fama and French 1992, 1998). A systematic-risk explanation is consistent with the longterm persistence of some factor-return relationships, such as the book-toprice ratio in the U.S. and other global markets. In this view, it is more reasonable to believe that anomalous factors reflect stock risk than profit opportunities that have been ignored by the investment community for decades. Although factor returns may be strictly inconsistent with the beta of the capital asset pricing model, they may be consistent with multifactor models of systematic risk. In this explanation, market anomalies may be persistent and statistically significant, but they are not economically significant because they simply reflect additional risk. Because such explanations are dependent on the assumed risk model, the results are often inconclusive (Fama 1991).

Methodological Errors. Market anomaly studies may have methodological errors that make their conclusions unreliable. In particular, Ball, Kothari, and Shanken (1995) and Conrad and Kaul (1993) have noted significant errors in some key contrarian studies. Such errors put in doubt the contrarian interpretation of some market anomalies.

Data snooping. Data snooping is a fundamental critique of nearly all market anomaly studies. Intuitively, enough snooping of a database almost always uncovers some factor, or set of factors, that explains return over a given period. However, no matter how lengthy the historical period, in-sample significance is not necessarily indicative of out-of-sample reliability ( $L o$ and MacKinlay 1990). In addition, because market anomaly studies often use similar historical data, it should not be surprising when new studies find similar results.

Size Misinterpretations. Many market anomaly studies focus on the market-capitalization factor. Berk (1995) showed that even if a firm's operational size is unrelated to expected return, its market capitalization is likely to have a negative relationship with average return in cross-sectional regressions. Consequently, a cross-sectional relationship between market capitalization and return should not be interpreted as an anomaly or as evidence that small-cap stocks earn abnormally high returns. Berk showed that market capitalization is likely to proxy for omitted systematic-risk factors or empirical misspecification of an asset-pricing model. 
Attribute-Sorted Portfolios. Many empirical studies use the returns of attribute-sorted portfolios to study risk factors in asset-pricing models. Ferson (1998) provides a critique of the attribute-sorted methodology that is related to Berk's (1995) analysis (see also Lyon, Barber, and Tsai, forthcoming). Ferson has shown that such "spread" or long-short portfolios will appear to imply the existence of risk factors even when the attributes are completely unrelated to risk. Loadings on attribute-sorted long-short portfolios should not, in general, be confused with risk factors.

Feconometric Limitations. Ordinary least squares (OLS) regression, widely used in market anomaly studies, is highly sensitive to index misspecification and prone to estimating false anomalous relationships (Roll and Ross 1994; Kandel and Stambaugh 1995). On the other hand, generalized least squares (GLS) regression is theoretically much less sensitive than OLS regression to the inefficiency of the index. Notably, a recent re-examination of Fama and French (1992) using GLS regression found a statistically significant positive relationship with beta (Ledoit 1994). At a minimum, the evaluation of empirical results should include consideration of the financial integrity and representativeness of the index and the power of econometric methods.

Magrnified Returns. In some studies, large anomalous returns have been cited to support the view that the observed anomalies are neither ephemeral nor consequences of misestimated or omitted risk factors. For example, Lakonishok, Shleifer, and Vishny (1994) reported 7-8 percent a year in extra returns on value stocks. Many of these studies, however, used two procedures-a long-short portfolio framework and multifactor valuation-that tend to magnify portfolio returns without changing underlying factor-return relationships. For example, factor returns may be associated with a long equal-weighted portfolio of top-decile stocks and a short equal-weighted portfolio of bottomdecile stocks from some stock universe ranked according to some stock attribute. This long-short equity strategy framework leverages index-relative returns and generally substantially increases residual risk (for further analysis, see Michaud 1993). In the case of numerous market anomaly long-short framework studies, portfolio residual risk levels are often substantially greater than what would be acceptable for most institutional investors. As another example, a forecast may be based on a combination of positive significant factors. This procedure may synergistically increase the information in the factor combination according to the mathematical/statistical properties of multiple valuation models (Michaud 1990). Consequently, large abnormal factor returns may simply indicate the use of procedures that magnify returns but do not provide incremental evidence of economic significance. 


\section{Institutional Style Factors}

Data snooping is a particularly pervasive critique of the economic significance of stock factors in market anomaly studies. In order to address the issue, a global equity market factor-return database was developed beginning in December 1990 to "forward test" various historical stock factors for their practical investment value. Sixteen beginning-of-the-month candidate stock forecast factors, beta, sector, index membership, and subsequent monthly total return were tabulated monthly. The factor values and regressions were defined according to the data and regression properties given below and in Appendix A. In early 1991, when the database was being developed, no prospective information on factor-return relationships was known. It was entirely possible that none of the candidate factors would be found to be statistically or economically significant.

An important additional limitation of many market anomaly studies is that the results may not be relevant for institutional active equity management. Typically, the active equity manager's role is to outperform a given index within a multifactor forecast framework. Consequently, understanding indexrelative systematic risk-adjusted return in a multifactor context is typically the active manager's relevant investment objective. In contrast, the focus of many market anomaly studies is the return premium (return net of the local interest rate) for individual factors. In addition, the stocks included in many market anomaly studies may not be those used in institutional portfolios. In practice, institutional asset managers may devote a significant effort to identifying a universe of investment-grade stocks, often in terms of minimum information availability. Also, to control the reliability of the forecast, institutional portfolios are typically mandated not to exceed 6 or 8 percent annual residual risk. ${ }^{1}$ Consequently, popular long-short market anomaly methodologies are often inappropriate measures of factor-return relationships in practice.

\footnotetext{
IThe amount of residual risk assumed by an asset manager should be closely related to the assumed level of information in the return forecast and estimation error in the risk model. See Michaud (1993) for further discussion on forecast reliability risk.
} 


\section{Regiression Design}

Multivariate linear regression is generally the statistical meihod of choice for measuring the relationships among stock factors for active stock selection. The regression should conform to principles of modern investment theory and optimal multiple valuation model design. That is, the regression should take into account the following practical investment issues:

- The index has no active risk.

- Index-relative systematic risk-adjusted return is often the appropriate return objective.

- Most indexes of interest are capitalization weighted.

- The distribution of factor values may have little investment content and may be counterproductive in regression estimation.

- Monthly horizons are often the forecast period of practical investment interest.

- Factors are defined consistent with the expectation of a positive relationship with ex post return.

- Stocks included in the regression should possess a level of information consistent with institutional investment-grade securities.

All reported regressions from the database satisfy those conditions. Specifically, the regressions are capitalization weighted and based on indexrelative monthly total returns, normalized and standardized factor values, investment-grade stocks, and systematic risk adjustment.

The pooled time-series regression coefficients and $t$-statistics for the factors are based on the Fama-MacBeth (1973) methodology. That is, the time-series average and $t$-statistic of the average of each month's factor regression coefficients are reported. A simple and useful approach to systematic risk adjustment is to include beta and dummy variables for sector and index membership. One benefit of this simple risk-adjustment procedure is that only current data are needed to define the regression for any monthly period.

During the nearly eight years since the project was initiated, the database has been redefined several times. In particular, the database has been expanded to include a number of additional countries and stocks within markets. In a limited number of cases, the previous unavailability of factor values may have introduced some look-ahead bias. These instances are largely limited to the normalized-earnings-to-price ratio, dividend discount model (DDM) alpha, and specific return reversal in the U.S. market, particularly in the early months of the development of the database and for an occasional month in other markets. Because the database represents an ongoing investment process, it is also inevitably affected by attempts to improve accuracy, 
remove software bugs, refine factor computations, and expand its applicability. In nearly all cases, the objective has been to sharpen the image of underlying factor-return relationships rather than alter them. With the exceptions noted, nearly all of the changes were implemented on a going-forward basis. Consequently, the database should be reasonably useful for examining factor returns in an active stock selection framework that is relatively free of the biases from data snooping.

The seven-aggregate-factor framework described in a subsequent section is a separate issue. It was developed from the original set of 16 univariate variables in mid-1994. A similar aggregate-factor framework had been developed in mid-1992 and had been used for stock selection from that time onward. A delay for developing an aggregate-factor model was inevitable because it required the accumulation of a sufficient amount of univariate variable data before statistical procedures, such as factor analysis, could be applied. The definition and analysis of the aggregate factors is discussed further in the following sections.

\section{Univariate Factor Attributions}

Table 4.1 provides the 16 univariate capitalization-weighted stock factor regression coefficients in basis points (bps) for Japanese stocks relative to the MSCI (Morgan Stanley Capital International) country index for Japan, risk adjusted for beta, sector, and index membership. Three sets of monthly regression coefficients are given-October 1995, November 1995, and December 1995. In addition, the results of a five-year pooled average of monthly regression coefficients and $t$-statistics of the average coefficients, from January 1991 to December 1995, are given. For example, the book-toprice ratio is a statistically significant factor over the five-year period. The data indicate that an MSCI Japan index-relative risk-adjusted return of $40 \mathrm{bps}$, on average, would have been experienced over the five-year period for a 1 standard deviation tilt on the book-to-price ratio, gross of costs. The database consisted of nearly 60,000 firm-months of monthly stock factor returns in Japan during this period.

Univariate analysis provides a simple description of the underlying data and is a traditional approach to the analysis of factor-return relationships. However, univariate analysis provides limited useful information for forecasting return in practice. One important reason for this limitation is that a variable with significant explanatory power in isolation from other variables may become dominated when combined with other factors. Issues of consequence include factor interrelationships and factor-return dynamics. In the following sections, multiple regression techniques are applied to properly assess historical factor relationships that may be useful in an institutional multifactor forecast framework. 
Table 4.1. Univariate Factor Regression Analysis for Japan, January 1991-December 1995

\begin{tabular}{|c|c|c|c|c|c|}
\hline \multirow[b]{2}{*}{ Factor } & \multicolumn{2}{|c|}{ Average } & \multicolumn{3}{|c|}{ Coefficient } \\
\hline & Coefficient & $t$-Statistic & $\begin{array}{c}\text { October } \\
1995\end{array}$ & $\begin{array}{c}\text { November } \\
1995\end{array}$ & $\begin{array}{c}\text { December } \\
1995\end{array}$ \\
\hline Earnings-to-price ratio & 9 bps & 0.7 & 126 bps & $-141 \mathrm{bps}$ & $-50 \mathrm{bps}$ \\
\hline ratio & 6 & 0.4 & 110 & -55 & 24 \\
\hline $\begin{array}{l}\text { Book-to-price ratio } \\
\text { Cash-earnings-to-price }\end{array}$ & 40 & 2.7 & -48 & 46 & 211 \\
\hline ratio & 13 & 0.9 & -39 & -68 & -48 \\
\hline Dividend yield & 34 & 2.7 & -19 & 31 & 97 \\
\hline Sales-to-price ratio & 17 & 2.0 & -101 & 20 & 89 \\
\hline $\begin{array}{l}\text { Normalized-earnings-to- } \\
\text { price ratio }\end{array}$ & 29 & 2.2 & -3 & 92 & 193 \\
\hline DDM (alpha) & 20 & 1.7 & 14 & -46 & 105 \\
\hline $\begin{array}{l}\text { Change in analyst } \\
\text { earnings growth rates }\end{array}$ & -2 & -0.2 & 45 & 27 & -82 \\
\hline $\begin{array}{l}\text { Trend in analyst revisions } \\
\text { Five-day specific return }\end{array}$ & 2 & 0.3 & 72 & 32 & -69 \\
\hline $\begin{array}{l}\text { reversal } \\
\text { Thirty-day specific return }\end{array}$ & 48 & 3.8 & -56 & 135 & 66 \\
\hline reversal & 58 & 4.5 & 3 & 143 & -25 \\
\hline Market capitalization & 2 & 0.1 & 20 & 67 & 154 \\
\hline Analyst neglect & -10 & -0.7 & -20 & 53 & 80 \\
\hline $\begin{array}{l}\text { Historical four-year } \\
\text { earnings growth }\end{array}$ & -20 & -1.7 & 20 & -20 & -25 \\
\hline Earnings torpedo & 4 & 0.5 & -3 & -23 & 14 \\
\hline
\end{tabular}

Note: The results shown are based on monthly data. The entire period contained 59,866 firmmonths of data. The October 1995 period contained 1,569; the November 1995 period contained 1,572; and the December 1995 period contained 1,581.

Multiple regression analysis can have practical investment limitations if not used appropriately. Multiple regression coefficients of strongly correlated variables are likely to be highly unstable and may be unintuitive. The number of variables in the regression may also be of consequence for successful forecasting; increasing the number of variables may increase in-sample explanatory power but may also reduce out-of-sample forecast power. To approximation theorists, this is the well-known tiger-in-a-cage principle.

The issue of designing an optimal framework for forecasting return is not simply one of extracting maximum information from historical data. Active managers often use a multiple valuation model as a Bayesian framework for including exogenous information in the return forecast. Having a large number of correlated factors may make using the results of a historical regression difficult for understanding and forecasting factor relationships. A parsimonious, but comprehensive, representation of the active-return-generating pro- 
cess with relatively uncorrelated factors that have intuitive investment content may sacrifice in-sample fit for increased ability to effectively use exogenous information for forecasting return (Michaud 1990). One useful statistical procedure for developing an optimal multifactor forecast framework (i.e., factor analysis) will be described in the next section.

\section{Aggregate Style Factors}

One approach for increasing the usefulness of multiple regression estimation for forecasting return in a Bayesian framework is to identify a limited, yet comprehensive, set of low-correlation, investment intuitive, "aggregate" factors to represent the original set of 16 univariate "micro" factors. Factor analysis is the multivariate statistical procedure of choice for identifying a parsimonious set of low-correlation aggregate factors to describe the underlying data structure spanned by a given set of variables. In a process that can be described as "identification by the company it keeps," factor analysis helps to identify underlying macro or "style" factors that may characterize the individual micro factors that "load" together. In addition, factor analysis procedures can be useful for suggesting appropriate weightings of micro factors to define macro style factors. Multiple regression, based on factor analysis style factors, may provide a clear, stable, more useful description of factor-return relationships in a market for out-of-sample forecasting than univariate regression.

Factor analysis studies of the 16 forecast variables in Table 4.1 were performed. Based on the analyses of monthly data for five developed markets-Japan, the United Kingdom, France, Germany, and the United States-seven aggregate style factors were identified. The seven style factors and their associated micro factors are

- earnings yield (earnings-to-price ratio and broker consensus forecasted earnings-to-price ratio),

- asset yield (book-to-price ratio, dividend yield, cash-earnings-to-price ratio, and sales-to-price ratio),

- normalized earnings yield (normalized-earnings-to-price ratio and DDM alpha),

- earnings trend (trend in analyst earnings estimates and change in onemonth earnings estimates),

- return reversal (5-day and 30-day specific return reversal),

- size (market capitalization and analyst neglect), and

- cyclicality (historical earnings growth rate and earnings torpedo).

The seven style factors are clearly identifiable in all five major equity markets during the time period studied. Ridge regressions were used to assist in 
defining variable weightings within an aggregate factor. Factor analysis studies for three roughly equal, mutually exclusive subperiods tested the robustness of the definitions of the aggregate factors. Few differences were found and all seem reasonably well explained by statistical variation. The most notable exception is the "cyclical" or business cycle factor, which is the least stable. All style factors were restandardized so that the standard deviation is equal to 1 in reported regressions.

A significant issue often arises in discussions of factor-analysis-defined factors for forecasting return. In any given measurement period, an aggregate factor constructed from factor analysis may be less related to return than some of its components. Does this observation imply that the aggregate factor is inferior as a basis of forecasting return than the more successful micro variables? The key issue is whether the aggregate factor represents an investment meaningful component of the active-return-generating process. If not, individual factors may be more useful. On the other hand, factor analysis style factors that reflect stable investment constructs may be a safer basis for forecasting out-of-sample return than individual micro variables. ${ }^{2}$

\section{Style Factor Attributions}

Table 4.2 provides capitalization-weighted multivariate regression coefficients of the seven aggregate style factors for Japan for monthly data for October 1995, November 1995, and December 1995 and the monthly average coefficients and $t$-statistics for the January 1991 to December 1995 period, risk adjusted for beta, index, and sector membership. The $t$-statistics in Table 4.2 indicate significant relationships for return reversal and normalized earnings yield. ${ }^{3}$ However, as in Table 4.1, note the substantial variability of the regression coefficients characteristic of monthly periods in the October, November, and December 1995 data. Table 4.3 provides the multivariate pooled regression coefficients for four developed markets: France, Germany, Japan, and the United Kingdom. Table 4.4 provides the $t$-statistics for the coefficients of Table 4.3 .

A comparison of the coefficients in the univariate regressions in Table 4.1 with the multivariate regressions in Table 4.2 is of interest. Return reversal appears more significant, with a larger coefficient and $t$-statistic, as an aggregate multivariate factor (Table 4.2) than as individual components in the

\footnotetext{
${ }^{2}$ Note that aggregate factors may exhibit synergistic characteristics in terms of having a stronger relationship to return than their components.

${ }^{3}$ Note that the sign for the cyclicality factor is not consistent with the prior of a positive relationship and is, therefore, not considered significant.
} 
Table 4.2. Style Multivariate Regression for Japan, January 1991December 1995

\begin{tabular}{|c|c|c|c|c|c|}
\hline \multirow[b]{2}{*}{ Factor } & \multicolumn{2}{|c|}{ Average } & \multicolumn{3}{|c|}{ Coefficient } \\
\hline & Coeffficient & $t$-Statistic & $\begin{array}{c}\text { October } \\
1995\end{array}$ & $\begin{array}{c}\text { November } \\
1995\end{array}$ & $\begin{array}{c}\text { December } \\
1995\end{array}$ \\
\hline Asset yield & $18 \mathrm{bps}$ & 1.6 & $-93 \mathrm{bps}$ & $-37 \mathrm{bps}$ & $58 \mathrm{bps}$ \\
\hline Cyclicality & -12 & -1.9 & -45 & -11 & -30 \\
\hline Earnings trend & 4 & 0.7 & 47 & 20 & -63 \\
\hline Earnings yield & -10 & -0.6 & 187 & -114 & -129 \\
\hline $\begin{array}{l}\text { Normalized earnings } \\
\text { yield }\end{array}$ & 32 & 2.9 & -29 & 112 & 200 \\
\hline Return reversal & 67 & 6.2 & 24 & 155 & 50 \\
\hline Size & -9 & -0.6 & -7 & 90 & 104 \\
\hline Beta & 15 & 0.9 & -54 & 161 & 124 \\
\hline Index member & -3 & -0.1 & 104 & -86 & -161 \\
\hline
\end{tabular}

Note: The data shown are based on monthly data.

Table 4.3. 5:yle Mulvivariate Coefficients, January 1991-December 1995

\begin{tabular}{lcccc}
\hline Factor & France & Germany & Japan & United Kingdom \\
\hline Asset vield & 3 bps & 17 bps & 18 bps & -11 bps \\
Cyclicality & -3 & -1 & -12 & -5 \\
Earnings trend & 14 & 32 & 4 & 31 \\
Earnings yield & 11 & -8 & -10 & 28 \\
Normalized earnings yield & 13 & 16 & 32 & 4 \\
Return reversal & 30 & 46 & 67 & 74 \\
Size & 28 & -44 & -9 & 7 \\
\hline
\end{tabular}

Table 4.4. Style Mumivariate Statistics, January 1991-December 1995

\begin{tabular}{lccrc}
\hline Factor & France & Germany & Japan & United Kingdom \\
\hline Asset yield & 0.2 & 1.4 & 1.6 & -0.8 \\
Cyclicality & 0.2 & -0.1 & -1.9 & -0.4 \\
Eamings trend & 1.2 & 3.1 & 0.7 & 3.5 \\
Eamings yield & 0.7 & -0.5 & -0.6 & 1.9 \\
Normalized earnings yield & 0.9 & 1.1 & 2.9 & 0.4 \\
Return reversal & 2.0 & 4.2 & 6.2 & 6.6 \\
Size & 1.6 & -2.6 & -0.6 & 0.5 \\
\hline
\end{tabular}


univariate analysis (Table 4.1); normalized earnings yield appears more significant in the multivariate analysis, but asset yield appears less significant, with a less large coefficient relative to most of its univariate components. Further analysis showed that the average univariate regression coefficient for asset yield was 30 with a $t$-statistic of 2.5 , indicating that the multivariate framework is primarily responsible for the smaller coefficient and $t$-statistic for the asset yield style factor in this case. Few differences were found with factors that are not statistically significant.

The data in Table 4.5 include the style factor $t$-statistics for the four developed markets of Table 4.4 plus the United States. Because of data limitations for the U.S. market, the historical period in Table 4.5 begins in July 1992 and covers the five-year period ending in June 1997.

Table 4.5. Shyle Multivariate t-Statistics, July 1992-June 1997

\begin{tabular}{lccccc} 
Factor & France & Germany & Japan & $\begin{array}{c}\text { United } \\
\text { Kingdom }\end{array}$ & $\begin{array}{c}\text { United } \\
\text { States }\end{array}$ \\
\hline Asset yield & -1.4 & 0.1 & 1.8 & -0.5 & -0.3 \\
Cyclicality & 0.1 & -1.1 & -0.1 & -1.0 & -0.4 \\
Earnings trend & 2.4 & 2.8 & 2.9 & 3.3 & 3.0 \\
Earnings yield & 0.9 & 0.7 & 0.2 & 1.8 & 0.9 \\
Normalized earnings yield & 0.5 & 0.7 & 1.5 & 0.6 & 2.7 \\
Return reversal & 2.4 & 4.1 & 6.8 & 6.5 & 2.2 \\
Size & 1.0 & -2.1 & -2.3 & -0.5 & 1.0 \\
\hline
\end{tabular}




\section{Global Style Analysils}

A cursory inspection of the $t$-statistics in Tables 4.4 and 4.5 reveals that the majority of individual style factors are not statistically significant. As a first order consideration, it is of interest to test whether the data as a whole are statistically significantly different from random. Lack of significance could result if the number of observations is insufficient or if the seven-style framework is of little value for explaining index-relative risk-adjusted return in global equity markets. Hotellings T-square tests of the monthly riskadjusted regression coefficients for the four-country, five-year data in Tables 4.3 and 4.4 and the more recent five-country, five-year data in Table 4.5 indicate significance at the 0.01 percent level or less. It is safe to conclude that the data are not insignificant. ${ }^{1}$

Market anomalies have been associated with the January seasonal effect. For a recent discussion, see Hawawini and Keim (1998). The possibility exists that January data are largely responsible for the statistically significant relationships observed in the multivariate regression style factor data. The impact of the January seasonal effect was tested by eliminating the month of January and re-estimating the regressions. The results were essentially unchanged in both time periods.

Additional issues of fundamental interest are whether the seven-factor style framework is useful for explaining index-relative risk-adjusted returns in a given global equity market for these two historical periods and what style factors, if any, are related to return in all four/five equity markets. To test these questions, Hotellings T-square tests were performed for both time periods and data sets. The null hypothesis rejection probabilities are given in Table 5.1 and Table 5.2. Table 5.1 provides the rejection probabilities for the significance of the seven-factor style framework in each country for the indicated time periods. Table 5.2 provides the rejection probabilities for the significance of a style factor for the five countries listed in Table 5.1 in the indicated periods.

The results in Table 5.1 show that, except in France in the 1991-95 period,

II am particularly indebted to J. Shanken for noting the importance of Hotellings T-square analyses for these data. 


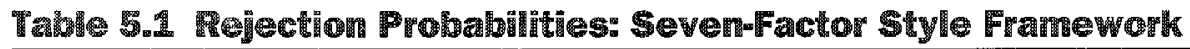

\begin{tabular}{lcc}
\hline Country & $\begin{array}{c}\text { January 1991- } \\
\text { December 1995 }\end{array}$ & July 1992- \\
June 1997 \\
\hline France & $22 \%$ & $5 \%$ \\
Germany & 0 & 0 \\
Japan & 0 & 0 \\
United Kingdom & 0 & 0 \\
United States & - & 0 \\
\hline
\end{tabular}

Table 5.2 Rejection Probabilities: Style Factors in Global Equity Markets

\begin{tabular}{lcc}
\hline Factor & January $1991-$ & July $1992-$ \\
\hline Asset yield & December 1995 & June 1997 \\
Cyclicality & $19 \%$ & $42 \%$ \\
Earnings trend & 43 & 30 \\
Earnings yield & 0 & 0 \\
Normalized earnings yield & 35 & 43 \\
Return reversal & 5 & 10 \\
Size & 0 & 0 \\
\hline
\end{tabular}

the seven-factor style framework appears useful for explaining index-relative risk-adjusted return. The results in Table 5.2 show that there is insufficient evidence that three style factors (asset yield, cyclicality, and earnings yield) are useful for explaining return in all markets in the data set. The style factors that are reasonably significant in all markets are earnings trend, return reversal, and normalized earnings yield. The apparent significance of the size factor in the 1991-95 period is problematic; the largest size factor $t$-statistic in Table 4.4 is negative for Germany. A negative sign is inconsistent with the sign prior for the size factor. Therefore, the T-square test statistic is not indicative of statistical significance because it does not consider sign and is influenced by large negative values. In only one other instance, France, is the $t$-statistic for size nearly significant and positive in Table 4.4. Consequently, there is insufficient evidence in either period consistent with significance of the size factor. In the context of many other studies of market anomalies, perhaps the most notable result in Table 5.2 is the nonsignificance of the risk-adjusted asset yield style factor.

An issue of interest is whether the data are consistent with the hypothesis that the factor-return relationships are similar across global markets. A conservative analysis-of-variance test indicated that factor-return relation- 
ships are unlikely to be similar at the 5 percent level for the four-country data and at the 1 percent level for the five-country data. ${ }^{2}$ It can be safely concluded that the data, when significant, are most consistent with factor-return relationships that are largely country specific.

Tests of the more general statistical hypotheses concerning the limitations and the reliability of the information in the regression data allow a more detailed analysis of the $t$-statistics and regression coefficients in Tables 4.34.5. At the usual 5 percent significance level, the data in Tables 4.4 and 4.5 indicate that from two to four factors are consistent with sign priors and are statistically significant and anomalous in these global equity markets and two time periods. Earnings yield is significant only in the United Kingdom, size is insignificant in all markets, and asset yield is significant only in Japan and only in the most recent period. On the other hand, normalized earnings yield is useful in some markets, earnings trend in many, and return reversal in all markets in these two time periods. To the extent that evidence for statistically significant market inefficiencies exists, the inefficiencies are either relatively short-term trading errors (return reversal) or largely associated with specific markets. A notable difference between the data in Tables 4.4 and 4.5 is the earnings trend factor, which is significant in all five markets for the more recent period.

The factor-return relationships reflected in Tables 4.3-4.5 are different from those of some well-known empirical studies, such as Fama and French (1992). ${ }^{3}$ Apart from the time period analyzed, obvious reasons for differences include the econometric estimation framework, a database designed to minimize data snooping, and investment-grade stocks in an index-relative context. To the extent that data snooping has been minimized and timeperiod-dependency issues are not dominant, the style factor-return relationships that emerge here may simply represent a more realistic and relevant forecast framework.

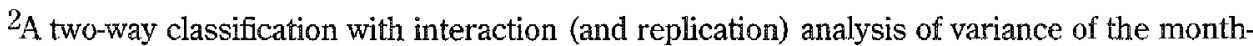
by-month regression coefficients was performed. The results showed that the interaction term, which indicates a country-specific factor relationship, is significant at the 5 percent level for the four-country data and at the 1 percent level for the five-country data. The test is conservative because only a few factor's are likely to have substantial interactions, although the majority may be negligible, and because the standard deviation of the regression coefficients are roughly the same for each market.

In some instances, when the estimation framework is similar, such as Lakonishok, Shleifer, and Vishny (1994 Table IV), the results for variables such as earnings-to-price ratio, book-tomarket ratio, and capitalization are somewhat similar. Roll (1995) also found that capitalization is dominated by other variables in a multivariate context.
} 
Tests of the effect of the beta, sector, and index risk-adjustment process indicated few significant changes in anomalous factor relationships. ${ }^{4}$ Because market capitalization may proxy for misestimated or omitted systematic-risk factors, the results are consistent with the hypothesis that relevant risk factors have not been ignored (Berk 1995). One alternative explanation of the results is that remaining significant factors may be consequences of the limitations of index misspecification and econometric estimation. Note, however, that capitalization-weighted regression is a form of GLS (generalized least squares) estimation that may mitigate the impact of index misspecification.

\footnotetext{
${ }^{4}$ Roll's (1995) risk-adjustment methodology for his data increased the statistical significance of market anomalous factors. Beta and sector risk adjustment in Table 4.5 led to a mix of increases and decreases of factor $t$-statistics with little discernible pattern. Exceptions are return reversal in France and the United States and asset yield in Japan, which became significant with risk adjustment. Roll's methodology applied to the data in Table 4.5, using beta and sector membership as risk factors, also led to a mix of increases and decreases of factor significance. The number of time periods of the data relative to the number of risk factors, however, limited the reliability of the analysis in this case. Note that, in contrast to the Roll (1995) results, the risk-adjustment process used in defining the regression in Tables 4.3-4.5 used beginning-ofmonth data only and did not require a stationarity assumption.
} 


\section{Market Efficiency and Factor Persilstence}

The evidence presented in the previous chapter indicates that some statistically significant risk-adjusted style factors exist in these global equity markets and time periods. Do these results indicate that global equity markets are not efficient? Unless the style "inefficiencies" are explainable in some reasonable fashion, market efficiency is the most likely explanation. On the other hand, the existence of statistically significant and rationalizable style factors may indicate true market inefficiencies that may have real economic and persistent forecast value.

\section{The Irrational Behavioral Hypothesis}

Attempts to "explain" market inefficiencies have often invoked an irrational behavioral perspective. Recall that the results of the analysis-of-variance tests indicate that style factors are not the same for the four or five global markets. On the other hand, the psychological-based behavioral hypothesis assumes that investor behavior is motivated by universal laws of decision making. Unless psychological laws vary by country, the behavioral hypothesis is not validated. ${ }^{1}$ In addition, although the significance of the return reversal factor in Tables 4.4 and 4.5 is arguably consistent with an "overreaction" hypothesis, earnings trend, which is also significantly related to return in all markets in Table 4.5 , is not. Finally, the irrational behavioral hypothesis is not consistent with the insignificance of the asset yield and earnings yield factors in many markets, factors that are often associated with contrarian strategies and irrational investor behavior.

\section{A Rational Behavioral Hypothesis}

An alternative approach is to consider that some significant style factors may reflect rational investor behavior associated with cultural or sociological factors specific to a given market. Some anecdotal evidence may be gleaned

\footnotetext{
${ }^{1}$ Note that sociological, as opposed to psychological, laws may vary by country. This essential difference is often lost in applications to investment behavior,
} 
from instances when style factors vary from one market to another within the same period. For example, Table 4.4 shows that earnings trend is important in explaining active return in the United Kingdom but not in Japan. This result is not hard to rationalize. Many global investment managers have known that brokerage earnings estimates in Japan have often supported the corporate view of the firm; conversely, brokerage earnings estimates in the United Kingdom have been more investor oriented. Recently, the impact of foreign brokers in Japan and in other markets may be altering investment traditions and may be making earnings forecasts more relevant to stock pricing. The data in Table 4.5, which are for the more recent 1992-97 period, show that earnings trend in Japan and France is significant.

As another example, consider earnings yield in Japan and the United States in Table 4.5. By definition, corporate earnings should reflect a firm's financial health, and the earnings-to-price ratio should provide a simple estimate of expected return. In markets such as Japan, however, accounting standards and company practice may lead many investors to ignore a firm's reported earnings. In this case, an asset- or cash-based estimate of expected return, such as asset yield, may be a convenient earnings yield surrogate for Japanese investors. In the U.S. market, earnings yield is widely available investment information even at the retail investor level and may, as a consequence, have little power to explain subsequent excess return, particularly in a multivariate risk-adjusted context. On the other hand, the significance of normalized earnings yield may reflect an active-return-generating process that is increasingly being dominated by sophisticated asset managers in the U.S. market. Even the consistency of return reversal among markets may be less indicative of investor overreaction than the universality of trading errors and the bid-ask bounce. Note also that return reversal may vary substantially by market and monthly period.

\section{The Market Culture Hypothesis and Globalization}

A market culture explanation of market anomalies is a working hypothesis that may be useful for understanding the likely persistence of factors and for identifying additional profitable factors in global equity markets. However, the growing influence of foreign brokers and investors is likely to lead to increased homogeneity of the return-generating process in many markets. Nevertheless, the data suggest that useful information may be available by attending to the subtleties of the investment culture in a market.

Of course, not all factor-return relationships require rational explanation. Some significant style factors may simply be time-period-dependent artifacts of a nonstationary return-generating process (see Roll 1995 for evidence of 
nonstationarity). In addition, nonanomalous style factors may be useful for episodic factor weighting. Nonstationary factor relationships and dynamic style factor weighting are discussed in later chapters. As a practical working hypothesis, the existence of some medium-term inefficient factors in global equity markets seems to be reasonably consistent with available evidence. 


\section{Dynamic Factor Relationships}

Experienced investors are well aware that few factor-return relationships persist in sign and significance period-by-period. As the monthly data in Table 4.2 indicate, many factors, even when significant, may deviate substantially from long-term trends during shorter periods. These deviations may persist over extensive periods of time, with severe business consequences to asset managers. Knowing that a factor has worked well at forecasting return for the past 50 years is of little investment value if it has not worked for the past three years or will not for the next three. Successful active management must also be concerned with the shorter-term dynamic character of markets.

\section{Correlations across Time and Markets}

Table 7.1 provides 21 years of correlations of annual U.S. dollar total returns with six beginning-of-the-year stock factor values for all stocks in the MSCI (Morgan Stanley Capital International) country index for Japan. The average, standard deviation, and $t$-statistic (of the average) of the annual correlations for each factor are given at the bottom of the table. Note that the correlations reflect neither risk adjustment nor multivariate analysis. The data simply illustrate the dynamic character of factor-return relationships, even when significant, and their likely impact on business and investment risk over extended time periods.

In Table 7.1, all stock factors except for market capitalization have statistically significant average correlations for the 1975-95 period. This finding indicates that a portfolio tilted toward any of these five significant factors would have been likely to perform well over this period. However, a manager who chose (in hindsight) the single best predictive factor for this period in Japanthe book-to-price ratio-would have experienced two recent consecutive years (1991-1992) and three additional consecutive years (1982-1984) with little added value. Because perfect hindsight is not available in practice, consider a manager who used the popular earnings-to-price ratio to value stocks in Japan over this same period. In this case, in only two of the last five years and in only one of the six years starting from 1984 were the correlations sufficiently positive to provide significant added value (Bergstrom and England-Markun 1982). Such performance is likely to have serious business 
Table 7.1 Factor Correlations in Japan with Subsequent One-Year Total U.S. Dollar Return

\begin{tabular}{|c|c|c|c|c|c|c|}
\hline Year/Item & $\begin{array}{l}\text { Market } \\
\text { Cap }\end{array}$ & $\begin{array}{l}\text { Earnings to } \\
\text { Price }\end{array}$ & $\begin{array}{l}\text { Book to } \\
\text { Price }\end{array}$ & $\begin{array}{l}\text { Cash Earn- } \\
\text { ings to Price }\end{array}$ & DDM & $\begin{array}{l}\text { Normalized } \\
\text { Earnings to } \\
\text { Price }\end{array}$ \\
\hline 1975 & 0.22 & 0.19 & 0.14 & -0.03 & 0.24 & 0.19 \\
\hline 1976 & 0.11 & -0.01 & 0.03 & -0.11 & 0.00 & -0.05 \\
\hline 1977 & 0.19 & 0.08 & 0.46 & 0.27 & -0.06 & 0.01 \\
\hline 1978 & 0.32 & -0.02 & 0.26 & 0.12 & 0.09 & 0.10 \\
\hline 1979 & -0.08 & 0.03 & 0.12 & 0.13 & 0.02 & 0.08 \\
\hline 1980 & -0.02 & 0.16 & 0.06 & 0.16 & 0.14 & 0.09 \\
\hline 1981 & -0.33 & 0.19 & 0.25 & 0.21 & 0.11 & 0.17 \\
\hline 1982 & -0.07 & 0.25 & 0.08 & 0.03 & 0.31 & 0.26 \\
\hline 1983 & 0.16 & 0.11 & 0.01 & -0.05 & 0.24 & 0.23 \\
\hline 1984 & -0.10 & 0.00 & 0.02 & 0.02 & -0.09 & -0.06 \\
\hline 1985 & 0.08 & 0.06 & 0.25 & 0.12 & 0.01 & 0.08 \\
\hline 1986 & -0.13 & -0.02 & -0.07 & -0.02 & -0.14 & -0.15 \\
\hline 1987 & 0.19 & 0.12 & 0.26 & 0.13 & 0.13 & 0.20 \\
\hline 1988 & 0.07 & 0.06 & 0.12 & 0.09 & -0.06 & 0.07 \\
\hline 1989 & 0.52 & 0.03 & 0.13 & -0.03 & 0.00 & 0.05 \\
\hline 1990 & 0.11 & 0.15 & 0.16 & 0.11 & 0.17 & 0.16 \\
\hline 1991 & 0.11 & -0.01 & 0.07 & 0.03 & 0.05 & 0.04 \\
\hline 1992 & 0.03 & -0.01 & 0.04 & 0.03 & 0.02 & 0.02 \\
\hline 1993 & -0.18 & 0.11 & 0.27 & 0.23 & 0.23 & 0.27 \\
\hline 1994 & 0.33 & -0.17 & 0.25 & -0.07 & 0.05 & 0.14 \\
\hline 1995 & -0.12 & 0.21 & 0.07 & 0.13 & 0.18 & 0.19 \\
\hline Average & 0.07 & 0.07 & 0.14 & 0.07 & 0.08 & 0.10 \\
\hline Standard deviation & 0.20 & 0.10 & 0.12 & 0.10 & 0.12 & 0.11 \\
\hline$t$-statistic & 1.56 & 3.32 & 5.27 & 3.13 & 2.96 & 4.13 \\
\hline
\end{tabular}

consequences in the practical world of institutional investment management. Similar situations exist with other factors and in other markets.

Additional noteworthy issues are illustrated in the data of Table 7.1. For example, factors can differ significantly in predictive power in the same time period. In 1994, while the book-to-price ratio, market capitalization, and normalized-earnings-to-price ratio had positive correlations with return in Japan, the correlation for the earnings-to-price ratio was largely negative and the correlations for the cash-earnings-to-price ratio and DDM (dividend discount model) were insignificant. Also, the factor correlations vary markedly from one market to another. In similar analyses, it was found that while the bookto-price ratio was important in predicting returns in Japan and the United Kingdom, it was unimportant in Germany and of only marginal importance in France. 
The idiosyncratic nature of capital markets and their dynamic characteristics largely define the challenge to active global management. A tool for managing the dynamic character of factor returns for stock selection is explored further in the following chapter.

\section{Size and Serial Persistence}

Table 7.2 provides a summary of the serial persistence of monthly sign changes and $t$-statistics relative to random for each of the seven aggregate style factors in Japan for the 1991-95 period. The data are divided into two cases: those that are not adjusted for the mean value and those that are. Both cases are of interest. The data without mean adjustment represent the situation encountered by a manager with a tilt on a given factor. The meanadjusted data more accurately reflect the statistical character of the sign changes. In the unadjusted case, two factors are statistically significant at the 10 percent level-return reversal and size. The adjusted mean data show that

\section{Table 7.2 Aggregate Factor Monthly Sign Changes and t-Statistics: Japan, January 1991-December 1995}

\begin{tabular}{|c|c|c|c|c|}
\hline \multirow[b]{2}{*}{ Factor } & \multicolumn{2}{|c|}{ No Adjustment for the Mean } & \multicolumn{2}{|c|}{ Adjusted to the Mean Value } \\
\hline & $\begin{array}{c}\text { Sign } \\
\text { Changes }\end{array}$ & $t$-Statistic & $\begin{array}{c}\text { Sign } \\
\text { Changes }\end{array}$ & $t$-Statistic \\
\hline Asset yield & 31 & 0.4 & 33 & 0.9 \\
\hline Cyclicality & 35 & 1.4 & 37 & 2.0 \\
\hline Earnings trend & 27 & -0.7 & 31 & 0.4 \\
\hline Earnings yield & 29 & -0.1 & 29 & -0.1 \\
\hline Normalized earnings yield & 26 & -0.9 & 28 & -0.4 \\
\hline Return reversal & 23 & -1.7 & 30 & 0.1 \\
\hline Size & 23 & -1.7 & 23 & -1.7 \\
\hline
\end{tabular}

the sign persistence of return reversal is the result of its nonzero average value. On the other hand, the sign persistence of the size factor is not associated with its average value. Note that the marginally significant style factor (i.e., asset yield) and significant factor (i.e., normalized earnings yield) show no sign persistence. The data indicate that a persistent positive factor weight for a number of style factors, even when significant on average, may result in many time periods with unfavorable performance.

Successful active global stock selection may be less associated with longterm factor-return relationships than with effectively managing the dynamic character of markets. In practice, stock selection is often based on factors that 
may not be significant in the long term. ${ }^{1}$

The size factor is a case in point. In practice, investment professionals may use market size to forecast index-relative returns independent of the factor's long-term significance. The reason for this behavior is that the pattern of returns on small-cap stocks is often perceived to be strongly related to various economic and business cycle factors and epochs. This intuition is consistent with the persistence of the sign factor in Table 7.2 and illustrated in Figure 7.1. Consequently, although a constant factor weighting on size may be ineffective on average over long time periods, a significant factor weighting in some carefully chosen relatively short time periods may be very profitable.

Figure 7.1. Japan Monthly Index-Relative Return to Size

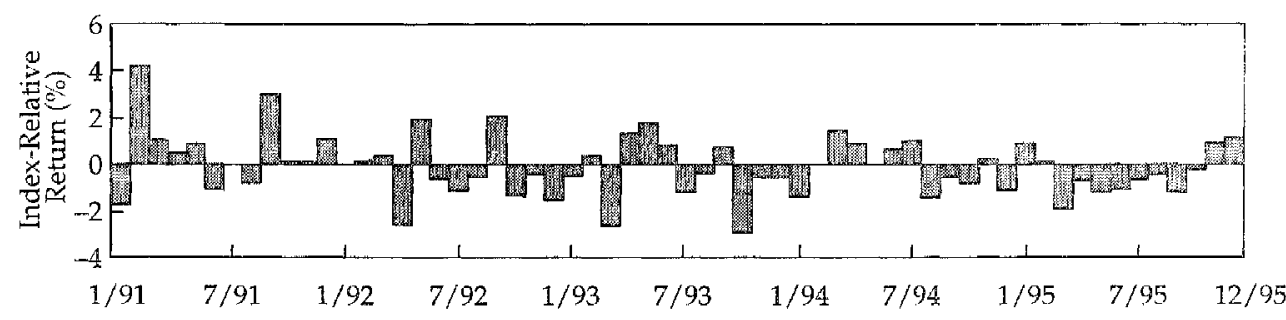

\footnotetext{
1 An advantage of the seven-aggregate-factor framework over commercial risk model factors as a source of style factors is that the former case was developed for forecasting returm, not risk.
} 


\section{Dynamic Factor Weighting}

It seems reasonable to assume that asset managers occasionally have insights about short-term factor-return relationships that may be relevant for forecasting return. Consequently, it is natural for a manager to consider a dynamic factor-weighting process for forecasting return when the process is reliably informed.

On the other hand, factor-weight forecasting is commonly perceived to be market timing on factors and has a dubious reputation among many institutional investors and consultants. Although ad hoc factor weighting has the virtue of practicality, the lack of rigor in implementation is a justifiable concern. In many cases in practice, ad hoc dynamic factor-weighting leads to lurches from one set of forecast factor weights to another, typically resulting in substantial forecast volatility and suboptimal investment performance. The problem is compounded because managers often formulate their factorreturn forecasts in univariate terms and have limited understanding of their multivariate implications.

The problem is less the lack of valid manager insights than of suboptimal implementation of the forecasts. The Theil mixed estimation procedure described below addresses many of the legitimate concerns with dynamic factor weighting in the context of multiple valuation stock selection. Used properly, it is likely to result in far less volatile and more reliable forecasts.

\section{Regression and Forecast Factor Weights}

Although useful for understanding historical relationships, multivariate regression coefficients are not typically used by institutional managers to forecast return. For example, a forecast of active return may consist of relative weightings of two-thirds and one-third for two style factors and zero for all others. Note that multiplication of the regression coefficients by a suitable constant allows conversion to an absolute sum-to-1 (or 100) relative-weighting scale without altering the level of information (correlation) of the regression with historical return. Note also that the size of the regression coefficients reflects the in-sample standard deviation of return, which is unknown when forecasting out of sample.

These practical considerations lead to a two-step procedure for defining 
a multiple valuation forecast-relative weighting of forecast factors and scaling the forecast. The first step relatively values factors in an absolute sum-to1 (or 100) framework that is based in part on regression analysis. The scaling step allows separate consideration of the level of forecast information and return variability in the forecast period (see the Michaud 1989 Appendix for a description of the scaling procedure).

\section{Theill Mixed Estimation}

Theil mixed estimation is a generalization of least squares linear regression that allows for optimally combining historical data with forecast information (Theil and Goldberger 1961; Theil 1971). It is useful for managing a dynamic multifactor stock selection process. It is also useful as an interactive feedback system for refining forecasts. The procedure allows the strategist to understand the implications of forecasts and levels of certainty for any subset of factors. Ex ante factor correlations may also be included as inputs. Theil weights often lie between forecasted and historical factor weights. Although the results may be qualitatively unsurprising, the procedure provides precise optimal weights under the assumptions.

As an illustration, consider the following stylized contrarian strategy of style factor weights for selecting stocks in Japan. The relative-weight forecasts are displayed in the second column of Table $8.1-25$ percent each for value factors (asset yield, earnings yield, and normalized earnings yield), -12.5 percent each for earnings growth factors (cyclicality and earnings trend), and zero weight on remaining factors. Note that the weights on reversal and size are not no-information forecasts. Relative-weight forecasts have an absolute sum-to-100 value. Assume that the style relative-weight forecasts have a standard error, as given in column three in Table 8.1, and that the forecast horizon is six months. Table 8.1 displays the average regression coefficients for the indicated five years of monthly historical data (absolute sum-to-100 normalized) and the Theil optimized factor weights (absolute sum-to-100 normalized). See Appendix B (p. 42) for further details of the estimation process.

Some caveats are in order. No statistical procedure is immune to bad forecasts or unexpected changes in the return-generating process. Because mixed estimation is so flexible, it is susceptible to misuse by those inexperienced with multivariate statistical techniques. In addition, mixed estimation assumes that priors are independent of historical data. But factor forecasts are seldom totally independent of historical data whether ad hoc or Theil procedures are used. In Theil factor-weight optimization, the problem is explicit rather than implicit. 
Table 8.1 Mixed Estimation Factor Weighting, Stylized Contranian Strategy, Six-Month Horizon: Japan, January 1992December 1997

\begin{tabular}{lcccc}
\hline Factor & $\begin{array}{c}\text { Prior } \\
\text { Weights }\end{array}$ & $\begin{array}{c}\text { PriorStandard } \\
\text { Errors }\end{array}$ & $\begin{array}{c}\text { Historical } \\
\text { Weights }\end{array}$ & $\begin{array}{c}\text { Theil } \\
\text { Weights }\end{array}$ \\
\hline Asset yield & 25 & 25 & 15 & 28 \\
Cyclicality & -12.5 & 12.5 & -2 & -11 \\
Earnings trend & -12.5 & 12.5 & 8 & -2 \\
Earnings yield & 25 & 25 & -5 & 17 \\
Normalized earnings yield & 25 & 25 & 15 & 23 \\
Return reversal & 0 & 12.5 & 42 & 14 \\
Size & 0 & 12.5 & -13 & -5 \\
\hline
\end{tabular}

Notes: The prior standard errors define forecast reliability over the forecast horizon. The forecast standard error is the standard error of the forecast multiplied by the square root of the number of periods in the horizon scaled to be consistent with the historical monthly regression data. The standard errors for the nonzero priors in the example reflect a reliability level associated with a $t$-statistic of 1 for the forecast horizon.

A better understanding of the implications of priors should be helpful in stabilizing and optimizing the process for forecasting factors and for stock selection. All else being the same, a Theil procedure is far less likely to result in excessive changes in factor weights than $a d$ hoc approaches. The level of reliability required to rationalize large factor-weight changes informs the analyst of the risks that are being taken. On the other hand, because Theil estimation allows better control of the forecast process, managers may be willing to adjust factor weights more frequently. These frequent adjustments may result in a "steady correction" process that is likely to decrease forecast volatility and increase reliability in practice.

The process of formulating a valid and useful forecast is the key to successful dynamic factor weighting. Many institutional investors use a variety of methods and sources of information for forecasting factor-return relationships. The objective of the Theil process is to provide a more complete understanding of the implications of forecasts in light of the historical data in a framework suitable for multifactor valuation.

\section{Extensions}

Regression estimation for forecasting can often be improved with Stein estimators (Judge et al. 1988). These estimators can be included to enhance the Theil mixed estimation of factor weights. Because the Theil procedure is a multivariate regression process, many test procedures can be applied to evaluate various hypotheses (Theil 1971,pp.350-351). Such topics are beyond the scope of this monograph. 


\section{Defining Value and Growth Stocks}

Many measures of a stock's value are used in practice. ${ }^{1}$ Most traditional value measures are ratios of a firm fundamental to price. The list of 16 factors in Table 4.1 contains 8 that are widely considered to be traditional value measures. These 8 measures are components of one of the three aggregate value style factors-earnings yield, normalized earnings yield, and asset yield-used in the regressions in Tables 4.2-4.5.

All eight univariate value factors have advocates and rationales for stock valuation. Asset yield value factors may be preferred to earnings-based factors because they are not as subject to the vicissitudes of accounting practices and may be less variable for economically sensitive companies. On the other hand, the earnings yield factors implicitly include a component of expected future growth of the firm, as well as cash distribution, as part of the valuation measure. Normalized earnings yield factors may be preferable to earnings yield factors because they may be less sensitive to the economic cycle. Such considerations may be particularly important in some global equity markets.

Evidently, many plausible measures of value exist. Are all such measures fundamentally similar; that is, is value single dimensional and reasonably well approximated by each univariate or aggregate value style factor? Alternatively, does more than one kind of stock value exist? The three value style factors that emerged in the seven-factor style framework indicate that value may be multidimensional; that is, at least three distinct kinds of risk-adjusted equity value styles exist. Is value multidimensionality an artifact of the research paradigm used to study the microforecast factors, or does it represent something fundamental in terms of understanding the return-generating process in global equity markets?

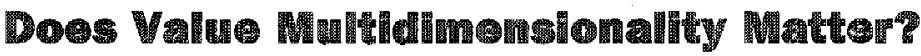

A key question is whether the three value style factors are useful for understanding the active-return-generating process in global equity markets

\footnotetext{
${ }^{1}$ The discussion follows Michaud (1998b).
} 
relative to simpler measures. One simple alternative is to equal weight all eight univariate or microfactors in the three value style factors as a unidimensional representation of value.

To put this question to a test, the $t$-statistics of the value style factor regressions in Table 4.5 were compared with $t$-statistics of the unidimensional value style measure, everything else being held constant. ${ }^{2}$ The regression was performed exactly as in Table 4.5. Table 9.1 summarizes the unidimensional and multidimensional value $t$-statistics for the value style factors in the U.S., U.K., and Japanese markets. The $t$-statistics in Table 4.5 for the three value style factors are reproduced for convenience in Table 9.1.

\begin{tabular}{|c|c|c|c|}
\hline Factor & Japan & United Kingdom & United States \\
\hline Unidimensional & 2.9 & 1.7 & 1.9 \\
\hline Asset yield & 1.8 & -0.5 & -0.3 \\
\hline Earnings yield & 0.2 & 1.8 & 0.9 \\
\hline Normalized earnings yield & 1.5 & 0.6 & 2.7 \\
\hline
\end{tabular}

Note: The data shown are based on pooled monthly data.

\section{Implications for Value Style Management}

The $t$-statistics for the unidimensional value style factor in the three markets are positive and reasonably significant. It is safe to conclude that risk-adjusted unidimensional value has been a relatively significant contributor to multivariate return in the three markets, on average, for this time period.

However, the multidimensional framework provides a more detailed view of the relationship of value to return. The asset yield factor is statistically significant only in Japan. Earnings yield is significant only in the United Kingdom. Normalized earnings yield is roughly significant in Japan and the United States. Consequently, each market has its own "value" characteristics during this period. Such insights can be very useful in formulating forecasts and understanding performance in a market.

A number of authors-such as Capaul, Rowley, and Sharpe (1993) - have popularized the use of the book-to-price ratio to classify value and growth investment styles in global equity markets. The notion is that if stocks are priced correctly, those with high book-to-price ratios will be priced based on

\footnotetext{
2The regressions are multivariate in both cases and include the remaining four aggregate style factors-size, earnings trend, reversal, and cyclicality-plus beta and index membership and sector dummy variables. For simplicity of presentation, the $t$-statistics of the aggregate and other factors in the multivariate regression are omitted.
} 
their current value and those with low book-to-price ratios will be priced based on their future growth potential. Typically, the categories are defined to be mutually exclusive: Fifty percent of stocks in a given stock universe are value and 50 percent are growth.

A number of consultants and providers of index data now track the performance of value and growth indexes using the book-to-price ratio as the measure of the value-versus-growth dimension. These indexes are used to measure the style performance of managers and to determine whether value or growth outperformed in a given time period.

Such procedures assume that value and growth are unidimensional and well represented by the book-to-price ratio. The evidence here indicates that neither assumption has been true for the three largest global equity markets in this recent five-year time period. Although asset yield, the aggregate factor that includes the book-to-price ratio, was an important measure of value in the Japanese market in the 1992-97 time period, it was not useful in either of the other two markets (the United Kingdom and the United States). In the one market-Japan-where asset yield was significant, normalized earnings yield was also significant. Consequently, an asset yield definition of investment style would not have been optimal in any of the three largest global equity markets for this five-year period. As the sole measure of global value, the book-to-price ratio criterion appears to have severe, if not fatal, active investment management and performance measurement limitations.

Factor-return relationships are generally time-period dependent. The data in Table 9.1 represent results for a relatively short, although investmentrelevant, period of time. On the other hand, the results of many long-term studies may be less convincing than they appear. As Lo and MacKinlay (1990) noted, the longevity of a factor-return study may provide little additional support of out-of-sample reliability or forecasting power. Even though timeperiod dependent, the data provide an investment-relevant view of factorreturn relationships that may be of interest to many global institutional investors.

\section{Defining Growth Stocks}

If the book-to-price ratio is a limited measure of value, it is likely to be similarly flawed as a growth-stock measure as well. However, the book-to-price criterion may have additional limitations for characterizing growth-stock investment.

Are growth stocks the polar opposite of value stocks? As implied by the criterion, do growth-stock managers invest only in stocks with low book-toprice ratios? In many institutions, growth-stock portfolios typically contain a substantial proportion of stocks with high book-to-price ratios because pru- 
dent institutional growth-stock managers are also concerned with stock price and relative valuation. Consequently, a growth-stock index defined solely by the book-to-price ratio may be seriously inconsistent with institutional practice. In addition, growth stocks are also likely to be multidimensional. The multidimensional seven-factor style framework presented here includes additional factors, such as earnings trend and earnings growth, that may be more appropriate than the book-to-price ratio for understanding growth stocks. Finally, in over-regulated economies, with rigid political and social structures or significant governmental corruption, the investment culture may be unconducive to indigenous entrepreneurial activity and the number of classical growth stocks in the market may be very limited. Single-factor characterizations of equity investment styles are often simplistic and seriously misleading in many markets and practical investment situations. 


\section{Global Equity Style}

Conventional definitions of global equity styles are typically generalizations derived from studies of the U.S. equity market. However, style multidimensionality, as well as market and period dependence, severely limit the benefits of simple style definitions and performance frameworks, particularly when applied to global equity portfolios.

\section{Market Style Multidimensionality}

The data in Tables 4.4 and 4.5 teach that an effective forecast of return for a given period consists of customized subsets of the seven style factors in each market. Suppose a stock selection model in a market consists of an equal weighting of asset yield, earnings trend, and specific return reversal style factors. Investment performance is unlikely to resemble a stylized value, growth, market-capitalization strata, or momentum investment strategy. Consequently, an effective return forecast may be inconsistent and inappropriately classified by two-factor or other conventional style analysis frameworks.

Effective style factors vary by time period as well as market. Changes in style factor effectiveness may reflect anticipatable changes in a market's investment culture and regulatory and monetary environment. The practice of dynamic factor weighting is likely to lead to an averaging of style forecast factors over time, adding a significant additional layer of complexity for classifying investment performance in terms of conventional fixed-factor style classifications.

\section{Market= and Poriod-Dopendent Style Factors}

Conventional global style analysis often assumes that style factors are the same across global equity markets. If, however, an effective global investment process requires style customization for each market, how useful is global style as a construct for characterizing investment strategy and analyzing performance?

Consider a global value equity manager. Table 9.1 indicates that global value is multidimensional and market dependent. An effective global value 
manager may use all three aggregate value style factors. Averaging the three value factor weights across global equity markets may lead to a relatively uniform pattern of value factors in the global portfolio. Consequently, effective global value style management may be ambiguous and ill defined relative to a style analysis that uses a single factor such as the book-to-price ratio.

More generally, nonvalue style factors may be significantly related to riskadjusted return in a global market. Astute global equity managers are likely to include all style factors in a market that they consider useful for stock selection. However, if a manager's investment process includes market-customized value and nonvalue style factors in each equity market, the global portfolio may often have nearly uniform weightings in many style factors. Consequently, an effective global stock selection investment process may often be essentially style neutral. Few, if any, style factors may be sufficiently prominent as to identify the investment strategy with any particular traditional investment style.

\section{Resolutions}

The ambiguity of global equity style indicates that it may often be appropriate to dispense with traditional labels and focus on stock selection effectiveness (see also Winston 1995). Conforming to a particular investment style should be of lower priority than effective asset management. If style investing limits investment performance, investment managers and fund trustees are well advised to abandon traditional style analysis.

Style analysis appears useful at the level of country markets. The sociopolitical culture of a market and economy may be reflected in the set of significant style factors that characterize the active-return-generating process. When significant and persistent, all such factors serve as a useful framework for stock selection.

Strict adherence to global value style, or any particular fixed-factor investment style, may be ineffectual or suboptimal and is not advisable. The limitations of global style analysis do not obviate the benefits of standard procedures for analyzing stock selection effectiveness and portfolio risk. Until the issue of global style is better understood, global asset managers may be at significant risk when evaluated with unsophisticated style analysis systems. As the impact of globalization on capital markets increases, the return-generating process in global equity markets may become more homogeneous, resulting in a convergence of effective style factors and perhaps better-defined global investment styles. 


\section{Summary and Conclusions}

A number of studies of market anomalies in global equity markets have observed statistically significant relationships between many stock factors and risk-adjusted returns. The economic significance of the results, however, is controversial. Because anomalous factors are the basis of most definitions of investment style analyses and institutional stock selection frameworks, determining their practical investment value is of great interest. A review of market anomaly studies reveals two rationales that are consistent with market inefficiency and economic significance and seven that are not. In addition, many studies have not been consistent with institutional active management mandates, which limits their practical relevance.

This monograph presented a new global equity database designed to address criticisms of market anomaly studies in an institutionally relevant framework. A seven-factor style framework was developed and estimates made for five major global equity markets. The results showed that from two to four factors are significant and vary by market. This new evidence alters the perception of the economic significance of market anomalies and style factors for institutional global stock selection in many markets.

The results are not consistent with the irrational behavioral hypothesis, but they are often consistent with a market culture or sociologically based rational behavioral hypothesis. This new rationale helps to support a limited market inefficiency prior and may increase confidence in the out-of-sample significance and reliability of some factors. On the other hand, the perception that large active returns are available from constant factor weighting with little business or investment risk, which was promoted by some earlier papers on market anomalies, appears to be largely a hoax.

Successful active stock selection may be more related to effective management of the dynamic character of markets than identification of anomalous factors. In practice, managers often have exogenous information on style factors that is useful for stock selection. The issue is less whether such information exists than whether it can be implemented in an effective fashion. A rigorous procedure for mixing active factor-tilt priors with historical data was given. The benefits include a reduction in forecast variability and the likelihood of more reliable performance. 
The observed multidimensionality and market- and time-period dependence of global style factors has important investment management implications. Little evidence was found that global equity style can be based on the same two factors, such as the book-to-price ratio and market capitalization, in all markets. Notably, the notion of global value investing is ambiguous and may be ineffectual. More generally, a conventional style framework often limits assessment of global manager effectiveness, and strict adherence to a fixed style framework may limit the ability to add value. Effective global equity portfolios are often style neutral. Dispensing with style labels and focusing directly on manager effectiveness may be the best approach to take in a global context. A valid factor-return estimation procedure, a market-customized, comprehensive style framework, investment insights, and a rigorous method for optimally mixing forecasts with historical data may significantly enhance global stock selection in an institutional context. 


\section{Appendix A: Database Description}

The database was originally designed to track and forward-test factor-return relationships on a monthly basis. G. Bergstrom proposed the initial list of 16 univariate variables. The database was developed as a framework for multiple valuation forecasting. ${ }^{1}$ The markets in the database initially included all MSCI (Morgan Stanley Capital International) Europe/Australasia/Far East countries except New Zealand. Most developed markets and some smaller markets have since been added, including, notably, the United States and Canada.

The original 16 factors, listed in Table 4.1, are

- current earnings-to-price ratio,

- broker consensus estimate earnings-to-price ratio,

- current book value-to-price ratio,

- current cash-earnings-to-price ratio,

- current annualized dividend yield,

- current sales-to-price ratio,

- normalized earnings-to-price ratio: inverse of book-to-price ratio divided by time-weighted return on equity,

- beta-adjusted three-stage dividend discount model alpha,

- magnitude in broker consensus change of earnings estimates,

- trend in broker consensus estimated earnings,

- five-day beta-adjusted price change,

- 30-day beta-adjusted price change,

- negative of the logarithm of total capitalization of the firm,

- earnings neglect: inverse of number of analysts providing estimates,

- historical four-year earnings growth rate, and

- earnings torpedo: difference of latest reported to forecast earnings divided by current price.

Three sets of variables were used in formulating risk-adjusted monthly returns: beta, index, and sector membership. Index membership is a dummy

\footnotetext{
1 During the development period and subsequently, a number of individuals contributed significantly to database design and management. These include Steve Silberberg, Raymond Mui, Vijay D'Silva, and Paul Erlich.
} 
variable that has a value of 1 for stocks outside the MSCI country equity index and 0 otherwise. Sector membership is a dummy variable that has a value of 1 for one of the nine sectors defined by MSCI: capital equipment, consumer goods, energy, finance, gold mines, materials, multi-industry, services, and utilities. In some global markets, a sector may have no corporate representation. One of the sector dummy variables was excluded in the regression in order to avoid singularity. Beta was unavailable in most months in 1991.

All the regressions used monthly total returns as the dependent variable and included a constant to define the coefficients in terms of index-relative returns. These conditions guarantee that the factor regression coefficients reflect index-relative return relationships, holding sectors, beta, and index membership constant in each monthly regression.

When 1 of the 16 microfactors was missing, its value was assumed to be zero. If fewer than 10 nonzero factor values existed in a given month, the variable was not included in univariate regression time-series averages.

July 1992 includes the beginning point of the bulk of the useful historical data in the database for the U.S. market. A reason for database limitations primarily affecting U.S. data is that data sources and identifiers are different for the United States relative to many international markets.

Factor analysis methods were used to define the aggregate style factors. A number of factor analysis procedures exist in the statistical literature. These procedures range from conservative methods with few assumptions to those with numerous assumptions that are primarily useful for specific applications. Although a number of factor analysis studies were performed on the 16 univariate variables, the results are based on one of the most conservative methods-principal factors analysis with orthogonal rotations. Comparison of the results of different factor analysis procedures indicates that the method is useful for understanding factor structure, given the objectives of the analysis.

The results reported for the aggregate style factors are for the most recent factor analysis study, completed in September 1994, and based on data from the beginning of the database through June 1994. An earlier factor analysis study was performed in the summer of 1992 and included at least a year's worth of cross-sectional monthly data for every market except the United States. The earlier study found evidence for five factors rather than seven. The basic difference between the earlier and more recent study is that the value factor in the later study had three components-earnings yield, asset yield, and normalized earnings yield. In hindsight, the evidence in 1992 was consistent with three value style factors and the current seven-factor style framework but was ignored because of the limited amount of data and the (then unconventional) investment character of a multidimensional view of value. See 
Chapter 9 for further discussion.

The criterion used for a stock to be included in the seven-factor style regression was that at least five of the seven aggregate style factors were available in a given monthly period. Such a criterion provides a minimum condition for information level, forecast quality control, and estimation reliability. When a factor had no data for fewer than 10 stocks in a month, it was omitted from the regression. This condition primarily affected the normalizedearnings-to-price ratio in the United States for months prior to July 1994.

If a variable was missing for a given stock, the corresponding aggregate factor was defined by rescaling the remaining weights in the aggregate factor so that they summed to 1 . If an aggregate factor was missing but five or more aggregate factors were available for a given stock, the missing aggregate factor was assigned a zero value. A minimum of 10 values of aggregate factors had to exist for the variable to be included in time-series averages and reported on a monthly basis.

A significant revision occurred for the normalized-earnings-to-price ratio in Japan. In a recent review of database integrity, the ex ante monthly data were found to be erroneous for the months March 1993, April 1993, February 1994, and April 1994. The problem was rectified by pasting the previous month's normalized-earnings-to-price data (two previous months in the case of April 1993) in the affected months. The data presented in this monograph include this database revision. 


\section{Appendix B: Theill Factor Weight Estimation}

Theil regression is the first step in a two-step development of a multiple valuation forecast that consists of relative factor weighting and forecast scaling. The unit for relative factor weighting is arbitrary and set to absolute sum-to-100 for convenience in this case. On the other hand, the historical regression coefficients reflect magnitude as well as relative factor weights. In addition, the Fama-MacBeth procedure requires averaging the crosssectional regression coefficients in each period. All these issues must be reconciled in the design of an appropriate Theil analysis procedure.

To make the scales of the prior and data comparable, one approach is to linearly scale the prior coefficients so that the root mean square sum equals the root mean square sum of the Fama-MacBeth average regression coeffcients. Because the aggregate factors are approximately uncorrelated and have standard deviation equal to one, the variance explained by the forecast prior after scaling and the average regression coefficients are about the same. The scale factor is also applied to the forecast prior standard errors. To conform to the forecast horizon assumption, the scaled prior standard errors are multiplied by the square root of the number of periods in the forecast horizon to obtain the standard deviations for a one-month forecast. The covariances of the forecasts are assumed to be zero. The mean and sample covariances of the monthly historical coefficients characterize the one-month historical data. The Theil procedure mixes historical and prior forecasts as described in Erlich, Lesniewski, and Michaud (1997). As a final step, the resulting Theil regression coefficients are absolute sum-to-100 normalized. 


\section{References}

Ambachtsheer, Keith, and James L. Farrell, Jr. 1979. "Can Active Management Add Value?" Financial Analysts Journal, vol. 35, no. 6 (November/December):39-47.

Ball, Raymond, S.P. Kothari, and Jay Shanken. 1995. "Problems in Measuring Portfolio Performance: An Application to Contrarian Investment Strategies." Journal of Financial Economics, vol. 38, no. 1 (May):79-107.

Banz, Rolf. 1981. "The Relationship between Return and Market Value of Common Stocks." Journal of Financial Economics, vol. 9, no. 1 (March):3-18.

Basu, Sanjoy. 1977. "The Investment Performance of Common Stocks in Relation to Their Price-Earnings Ratios: A Test of the Efficient Market Hypothesis." Journal of Finance, vol. 32, no. 3 (July):663-682.

Bergstrom, Gary, and Mark England-Markun. 1982. "International Country Selection Strategies." Columbia Journal of World Business, vol. 16, no. 2 (Summer).

Berk, Jonathan. 1995. "A Critique of Size-Related Anomalies." Review of Financial Studies, vol. 8, no. 2 (Summer):275-286.

Capaul, Carlo, Ian Rowley, and William F. Sharpe. 1993. "International Value and Growth Stock Returns." Financial Analysts Joumal, vol. 49, no. 1 January/ February):27-36.

Christopherson, Jon, and Dennis Trittin. 1995. "Equity Style Classification System." In The Handbook of Equity Style Management. Edited by T. Daniel Coggin and Frank J. Fabozzi. New Hope, PA: Frank J. Fabozzi Associates.

Christopherson, Jon, and C. Nola Williams. 1995. "Equity Style: What It Is and Why It Matters." In The Handbook of Equity Style Management. Edited by T. Daniel Coggin and Frank J. Fabozzi. New Hope, PA: Frank J. Fabozzi Associates.

Conrad, Jennifer, and Gautam Kaul. 1993. "Long-Term Market Overreaction or Biases in Computed Returns?" Joumal of Finance, vol. 48, no. 1 (March):39-64. 
Erlich, Paul, Andrew Lesniewski, and Richard Michaud. 1997. "Theil Mixed Estimation in a Fama-MacBeth Framework." Acadian Asset Management Technical Note (September).

Fama, Eugene. 1991. "Efficient Capital Markets: II." Joumal of Finance, vol. 46, no. 5 (December):1575-1618.

Fama, Eugene, and Kenneth French. 1992. "The Cross-Section of Expected Stock Returns." Joumal of Finance, vol. 47, no. 2 (June):427-466.

1998. "Value versus Growth: The International Evidence." Journal of Finance, vol. 53 , no. 6 (December):1975-99.

Fama, Eugene, and James MacBeth. 1973. "Risk, Return, and EquilibriumEmpirical Tests." Joumal of Political Economy, vol. 81, no. 3:607-636.

Ferson, Wayne. 1998. "The Alpha Factor Asset Pricing Model: A Parable." Presented to the Institute for Quantitative Research in Finance (Spring).

Graham, Benjamin, and David L. Dodd. 1962. Security Analysis. 4th ed. New York: McGraw-Hill.

Hardy, Steve. 1995. "Return-Based Style Analysis." 1995. In The Handbook of Equity Style Management. Edited by T. Daniel Coggin and Frank J. Fabozzi. New Hope, PA: Frank J. Fabozzi Associates.

Hawawini, Gabriel, and Donald Keim. Forthcoming 1998. "On the Cross-Sectional Behavior of Common Stock Returns: A Review of the Evidence in Markets around the World." In Security Market Imperfections in Worldwide Equity Markets. Edited by William Ziemba and Donald Keim. Cambridge: Cambridge University Press.

Judge, George, W. Griffiths, R.C. Hill, H. Lutkepohl, and T. Lee. 1988. Introduction to the Theory and Practice of Econometrics. 2nd ed. New York: John Wiley \& Sons.

Kandel, Shmuel, and Robert Stambaugh. 1995. "Porffolio Inefficiency and the Cross-Section of Expected Returns." Journal of Finance, vol. 50, no. 1 (March):157-184.

Keim, Donald. 1983. "Size-Related Anomalies and Stock Return Seasonality: Further Empirical Evidence." Journal of Financial Economics, vol. 12, no. 1:1332.

Lakonishok, Josef, Andrei Shleifer, and Robert Vishny. 1994. "Contrarian Investment, Extrapolation, and Risk." Joumal of Finance, vol. 49, no. 5 (December) :1541-78. 
Ledoit, Olivier. 1994. "Portfolio Selection: Improved Covariance Matrix Estimation." Sloan School of Management (November).

Leinweber, David, David Krider, and Peter Swank. 1995. "Evolutionary Ideas in International Style Management." In The Handbook of Equity Style Management. Edited by T. Daniel Coggin and Frank J. Fabozzi. New Hope, PA: Frank J. Fabozzi Associates.

Litzenberger, Robert H., and Krishna Ramaswamy. 1979. "The Effect of Personal Taxes and Dividends on Capital Asset Prices: Theory and Empirical Evidence." Joumal of Financial Economics, vol. 7, no. 2:163-196.

Lo, Andrew, and A. Craig MacKinlay. 1990. "Data-Snooping Biases in Tests of Financial Asset Pricing Models." Review of Financial Studies, vol. 3, no. 3 (Fall):431-468.

Lyon, John, Brad Barber, and Chih-Ling Tsai. Forthcoming February 1999. "Improved Methods for Tests of Long-Run Abnormal Stock Returns." Journal of Finance.

Michaud, Richard. 1989. 'The Markowitz Optimization Enigma: Is 'Optimized' Optimal?" Financial Analysts Journal, vol. 45, no. 1 (January/February):31-42.

1990. "Demystifying Multiple Valuation Models." Financial Analysts Journal, vol. 46, no. 1 (January/February):6-8.

1993. "Are Long-Short Equity Strategies Superior?" Financial Analysts Journal, vol. 49, no. 6 (November/December):44-49. School Press.

1998a. Efficient Asset Management. Boston, MA: Harvard Business 1998b. "Is Value Multidimensional? Implications for Style Management and Global Stock Selection." Joumal of Investing, voll. 7, no. 1 (Spring):6165.

Michaud, Richard, Gary Bergstrom, Ronald Frashure, and Brian Wolahan. 1996. "Twenty Years of International Equity Investing: Still a Route to Higher Returns and Lower Risks?" Joumal of Portfolio Management, vol. 23, no. 1 (Fall):9-22.

Michaud, Richard, and Paul Davis. 1982. "Valuation Model Bias and the Scale Structure of Dividend Discount Returns." Joumal of Finance, vol. 37, no. 1 (March):562-573.

Reinganum, Mark. 1981. "Misspecification of Capital Asset Pricing: Empirical Anomalies Based on Earnings' Yields and Market Values." Joumal of Financial 
Economics, vol. 9, no. 1 (March):19-46.

Roll, Richard. 1995. "Style Return Differentials: Illusions, Risk Premiums, or Investment Opportunities." In The Handbook of Equity Style Management. Edited by T. Daniel Coggin and Frank J. Fabozzi. New Hope, PA: Frank J. Fabozzi Associates.

Roll, Richard, and Stephen Ross. 1994. "On the Cross-Sectional Relation between Expected Returns and Betas." Journal of Finance, vol. 49, no. 1 (March):101-121.

Rosenberg, Barr, Kenneth Reid, and Ronald Lanstein. 1985. "Persuasive Evidence of Market Inefficiency." Journal of Portfolio Management, vol. 11, no. 3 (Spring):9-17.

Sharpe, William. 1988. "Determining a Fund's Effective Asset Mix." Investment Management Review (November-December):59-69.

-1992. "Asset Allocation: Management Style and Performance Measurement." Joumal of Pontfolio Management, vol. 18, no. 2 (Winter):59-69.

Theil, Henri. 1971. Principles of Econometrics. New York: John Wiley \& Sons.

Theil, Henri, and A.S. Goldberger. 1961. "On Pure and Mixed Statistical Estimation in Economics." International Economic Review, vol. 2, no. 1:65-78.

Winston, Kenneth. 1995. "Do International Styles Exist?" Presented to the International Equity Style Management Conference, New York (September). 